\title{
Violence and Social Media
}

\author{
By Murat Mengï \\ Seda Meng $\ddot{u}^{\dagger}$
}

The use of social media differs according to the socio-cultural, demographic and psychological aspects of individuals. People chat, share ideas and visual material, and feel that they satisfy their needs of belonging along with the groups they have joined. Social media is not only a domain of freedom where individuals express themselves overtly or secretly, but also an area where several ways of violence emerge or even a means used for some aspects of violence. Being an interactive medium and addressing quite a large number of users, social media issue has become rather sophisticated and problematic. As for the elements of violence in social media, the sites for women and child porn, visual material including excessive violence, campaigns of abuse towards certain people and institutions as well as black propaganda, attributing negative aspects, misdirecting people by assuming fake identities, different ways of theft in social media might be pointed out. The purpose of this study is to assess the media coverage regarding the news in which social media and violence coincide. Therefore, regarding the purpose of assessing the media coverage pertaining to the news in which social media and violence coincide, the news in three Turkish newspapers, namely, Zaman, Posta and Hürriyet have been examined with content analysis method for a three-month period, between November 1st and February 28th, 2014. The respective sampling was determined according to the highest circulation rate. The news have been examined according to the ratio of news coverage, news topics and news actors and the data obtained was processed quantitatively.

Keywords: content analysis, media, newspapers, violence

\section{Introduction}

It is an undeniable fact that technology has somehow pacified mankind. Once introduced, it is almost impossible to intervene in the advancement of technology. This situation is defined as Frankenstein Syndrome by Postman (1982/1994, p. 21). Therefore, social media structures itself independent of both individuals and government. In other words, it is hard to control it. As Baudrillard indicated, the media shows itself not in building an administrative power, but in deviating it. Thus, individuals get imprisoned in themselves and unavoidably alienated.

It is undoubtedly the human beings that have created social media and ensured its continuity. It is also the human beings who establish the social and ethical laws of the communication in social media. Therefore, social media is not a matter independent of those who use it. While McLuhan (as cited in Baban, 2012) considers the media as a powerful, determining, autonomous and

*Assistant Professor, Istanbul Arel University, Turkey.

${ }^{\dagger}$ Professor, Istanbul University, Turkey. 
active subject, Baudrillard (as cited in Baban, 2012) takes it as an object and indicate that the media has no usage value (Baban, 2012, p. 72). However, the point that both theorists agree with respect to the way they handle the media is technological determinism.

\section{Technological determinism is to explain social reality and historical processes on the basis of technological development and technological equipment. At the source of technological determinism lies the myth of autonomous technology. According to the respective myth, technology affects almost all levels of social organization from the forms of institutionalization to various ways of socialization. Hence, technology is considered as a power which forcibly surrounds or determines the actions of individuals. (Baban, 2012, p. 73)}

It is usually thought that technological development pacifies humanity. Once constructed, technology cannot be interfered. Thus, social media structures itself independent of both individuals and governments; it cannot be controlled. Again Baudrillard (as cited in Üşür, 1997, p. 29) have discussed that the media shows itself not in the creation of government, but in derailing of it. As a result, individuals get imprisoned in themselves and alienated. Gramsci (as cited in Üşür, 1997, p. 29) has analyzed the ideology which is not based on force as well as the indirect and acknowledged hegemony.

Different from Marx, Gramsci defines civil society as a domain constituting all the institutions out of production practices. Being the area of philosophical, literary, artistic, cultural etc. social practices, civil society is mainly the processing area of ideology on intellectual and moral levels and with respect to ideological struggles, it directly provides a basis for hegemony. Moreover, according to Gramsci (as cited in $\ddot{U}$ şur, 1997), ideology is functional in the configuration of production processes, and thus, is one of the fundamental social practices enabling the harmony between the infrastructure and the superstructure. (Üşür, 1997, p. 45)

Ideological dominance is structured within ideological instruments. Ideology is experienced through the rituals embedded in ideological instruments and emerges in a formation functioning mainly as the mechanism of naming and defining. This process is somehow the formation of subjects. Ideology names and identifies subjects. Hence, by means of the practices in these rituals, the subjects realize their positions through certain actions, such as defining, corresponding, worshipping, voting, defending their countries etc. Referring to Althusser (Üşür, 1997) has stated that the ideas of a subject are in fact his or her material actions defining the ideological instrument where the ideas of subjects arise from and taking place in the material practices organized by the rules of rituals. 
All kinds of consciousness are related to the production and transformation of social practices. Overall, ideology is a doctrine transforming mostly concrete political, socio-economic and cultural social theories about all institutions into practice ideologies can gain contemporary interpretations by getting inspired from the past (Kazanc1, 2001). According to both subjective and objective specifications; on the other hand, designation of social consciousness; is constituted by productive powers of individuals, conditioning of production relations as well as the production of consciousness by individuals themselves.

With respect to the views of Althusser and the others (Üşür, 1997), the discussions over ideology aim to put forth how, in fact, media creates the content consisting of violence, because, needless to say, ideologies arise from needs. In this sense, social media produces its own ideology in accordance with the needs it creates. This ideological production also brings the elements of violence with it. Overall, how needs transform to violence in social media in this section.

\section{The Concept of Violence}

Defined as "a way of action ... based on the power physically and materially to hurt other creatures or to be harmed" (Violence, n.d.a), the meaning of violence can be extended to "the exertion of physical force so as to injure or abuse" or "injury by ... distortion, infringement, or profanation" (Violence, n.d.b). Violence refers to killing, doing intentional harm, destroying, robbing, expelling as the five basic forms. Standing out especially, killing appears as the extreme limit of violence (Violence, n.d.a). Overall, violence refers to both the use of physical force intended to bring about destruction, injury or harm and also the exhibition of unjustified, wrongful and illicit actions meant to daunt and dismay.

Florea (2013) discusses that violence has so far been an indispensable part of our lives and asserts that either as children or adults, we can be seen frequently every day. It does not matter if we are children or adults, we might be the "aggressors, victims or witnesses of an aggression" (p. 350). Indeed as a consequence of political, economic or social reasons, in today's world any incident might easily trigger deep-rooted aggression.

As for the most common types of youth violence in social media, cyber bullying/victimization, harassment, electronic dating aggression/cyber-stalking, gang violence, peer-to-peer violence including school shootings and cybersuicide (Patton, Eschmann, \& Butler, 2013, p. 549) can be mentioned. Recently, new national phenomenon called internet banging, . Recently, new national phenomenon called internet banging, has been reported by media outlets, in which individuals involved in gangs or neighborhood factions use social media sites such as Twitter, Facebook and YouTube to incite dares, trade insults or make threats of violence which may result in homicide or victimization. These examples clearly indicate the extremities of the Internet abuses (Patton et al., 2013, p. 549). 
Furthermore, cyber-bullying can be defined as a form bullying which is exercised by using electronic technology including "cell phones, computers, and tablets as well as communication tools including social media sites, text messages, chat, and websites ... willful and repeated harm inflicted through the use of computers ... and other electronic devices" (Hinduja \& Patchin as cited in Best, Manktelowa, \& Taylor, 2014).

As for the examples of cyber-bullying, "mean text messages or emails, rumors sent by email or posted on social networking sites, and embarrassing pictures, videos, websites, or fake profiles" (What is Cyberbullying, n.d.) can be brought up. Van Laer (2013) defines the potentially harmful effects of cyber harassment as "emotional distress ... withdrawal from social network sites or even life itself". In the same way, referring to the study conducted by Ybarra and Mitchell (2004) indicate that cyberbullying may appear in different forms as seen in sending unwanted, derogatory, or threatening comments, spreading rumours, sending pictures or videos that are offensive or embarrassing by text, email, chat, or posting on websites including social networking sites (Görzig \& Frumkin, 2013). Generally speaking, utilization of electronic devices and social networks for the purpose of victimizing, harassing, distressing and pressurizing people seem to be the general aspects of cyber-bullying. Generally speaking, utilization of electronic devices and social networks for the purpose of victimizing, harassing, distressing and pressurizing people seem to be the general aspects of cyber-bullying.

So far as for the incidents of violence on social media; on the other hand, porn sites especially child porn, visual material displaying excessive violence, campaigns of abuse towards individuals and institutions or black propaganda, negative labeling, misdirecting people by establishing contact with fake identities (for instance, kidnapping or enslaving women and children on the pretext of employing them as well as the theft on social media (idea or money) can be mentioned. On the other hand, in the book The Technology of Nonviolence: Social Media and Violence Prevention, Bock (2012) states that social media could also be utilized to foresee and prevent the onsets of violence. Needless to say, rise of spontaneous, violent or abrupt occurrences, such as diseases, conflicts, contentions etc. can promptly be conveyed through social media.

In fact, violence arises in various ways through the mass media. Apart from the TV programs that reflect reality or rather convey it through a structuring process, representations of violence are observed in newspapers, magazines, particularly rap music etc. In the same way, violence can be noticed in toys and video games. In addition to all these, movies set up a category themselves. Moreover, the Internet content including particularly pornography as well as computer games can be mentioned. Generally, when the media texts, with a focus their contents, is considered, hardly any display where there is no visual representation of violence can be found (Yanıkkaya, 2009). At this point, there seems to be a little opportunity to escape from the content potentially emanating violent content. 
From another point, social media gives everybody the opportunity to write their own scenarios and become heroes or heroines. The way these people use social media would naturally differ as these scenarios are written by those having different values. Here, there is not a general, but an auto-control should be considered. However, this auto-control is related to value judgments and expression of identity of individuals. Probably social media makes everything, either positive or negative, is the world more conspicuous or normal. Social media produces the relationships within an intrinsic structure of meanings and discourses. The respective networks which were previously regarded as a realm of freedom for individuals in fact incarcerate them in virtual cages. The main purpose of joining the social media and surviving in that territory is the need of individuals to express themselves to the others and also expect to be perceived important by them. According to R. Sennet (2006/2009), the three deficiencies of structural change are; low corporate loyalty, reduction of informal confidence and decrease in corporate knowledge.

Considered with respect to voluntary participation of individuals to social and urban organizations, social media is a domain of social capital. However, being in this network sometimes may lead to tragedies as well, as particularly seen in the incidents of domestic or institutional violence. Especially children and young people may tend to display lack of "respect, responsibility, honesty, kindness, justice, or tolerance" (Willard as cited in Berson, Berson, \& Ferron, 2002). Emile Durkheim has already put forward how important it is for individuals to be a part of a class. "Identity is related to where you belong to rather than what you do; it is a general rule" (Sennet, 2006/2009, p. 55). Generally speaking, while this new media appears as a neo-public sphere, it also poses a threat for the violation of ethical codes.

Each society expects its members to display the ability to take action to some extent, to represent and play roles as expected. As a society gets fragmented, such actions begin to be expected from the members of these fragments rather than individuals. Then, actions are supported by silent expectations, not individual abilities just as the role of an actor or actress should be in harmony with whole formed by the other roles. According to Sennet (2006/2009), in such a social atmosphere structured accordingly, social ability tends to prevent individual probability rather than encouraging it. There is no freedom of speech, and thus, any reality and political action, because of these social mannerisms are devoid of rhetoric and self-directed. Instead of revealing individuals, actors try to allude to the things that has not been mentioned until then, but known already.

As Immanuel Kant stated, nothing good comes out of the warped wood of humanity. There will always be bad people and bad things will be committed. According to this view, cultural theorists deny the existence of evil. They are just softhearted social workers. Show them a serious crime; they will try to explain it on the basis of the repercussions of a bad childhood. (Sennet, 2006/2009, p. 40) 
As Heath and Potter (2004/2012) marked, the Industrial Revolution along with its consequences has been a disaster for human race. Living standards of those in developed countries have ascended; nonetheless, societies have gone inconsistent and dissatisfied. Consequently, human dignity has been undermined. Furthermore, these powers have also brought about psychological and physical problems especially in the third world. Hence, the nature has been destroyed mercilessly. In a world where modern technology has created a holistic hegemony and control system as well as nature has been systematically destroyed, people have unavoidably turned to nothing but excessively socialized and obsessed masses who are in strict conformity with the imposed order. As Guy Debord and Jean Baudrillard (as cited in Heath \& Potter, 2004/2012, p. 140) have indicated, in the Society of the Spectacle, we live in a world where everything is a representation or an illusion. The matrix is real and always with us. Then, who cares what is right or wrong?. Everything is just a struggle for by whom the reality is defined (Heath \& Potter, 2004/2012, p. 156).

Despite the use of easiness it provides to share different views and emotions, we can hardly say that social media has noticeably changed and shaped the real world. Twitter, Facebook and the other social networks function as platforms where individuals express their opinions about anything, anytime. Nevertheless, certainty and continuity of these ideas are quite debatable. Instantaneous approvals and quick transformations with regard to different ideas make us question the reliability of this medium. From this point of view, it can be suggested that social media is more effective as a means of advertising and marketing. Delivering products and providing services to customers quickly, continuously and interactively on social media has surpassed the traditional media.

Social media is an important area to realize social practices and sharing of realities. The way of using the information shared on social media brings up significant effects in economic, social and cultural dimensions. Masuda (as cited in Başaran, 2010) suggests that:

Information produces itself as it is used. Sharing of processes and information as a whole leads to more information production and sharing. Therefore, socio-economic development is noticed instantaneously. As a result, access to information by everyone in a society brings about a series of economic, cultural and political changes: centralization, standardization, abuse of labor and monopolies in industrial production would end and a pluralistic marketing conception will overcome. As more people would have access to more information, referendums could be held by just pressing a button; in addition, the privilege of the administrative elites to make decisions would be shifted by participatory democracy. Consequently, international harmony and understanding would be achieved. (p. 72) 
Despite the revolutionary model, if proper interventions are not made, information and communication technologies may cause the creation of " $a$ controlled society". During the last decade of the $20^{\text {th }}$ century, the developments and practices in information and communication technologies have been interpreted as the realization of the information society theses along with the developments leading to the new forms of society, economy, culture and politics. In this new form, image and reality are intertwined. Trying to experience and feel the reality without totally getting away from it while getting alienated from both society and themselves by gradually disappearing in virtual reality, there would be individuals have become rather important in the value system of this new social order.

Foucault suggests that there are four discourse "technologies" enabling individuals to understand and transform themselves: production technologies, sign systems, power and individuality. According to Foucault what is meant by "technology" is a series of discursive practices. Foucault's power technologies "determine the behavioral patterns of individuals and oblige them to encounter certain consequences and accept domination" (Foucault as cited in Motion \& Leich, 2007). While power technologies are imposed, identity technologies are chosen by individuals to create, change or transform identity.

Here the technology is public relations as discourse practice. Determining behavioral patterns, formation of identity and enabling the adoption of power technologies to manipulate individuals as desired are the responsibilities of public relations. Inefficiency in expressing oneself along with lack of confidence and knowledge is a serious obstacle between administration and people. Therefore, it gets really difficult for the public to understand the rules and regulations developed by administration. At this point, the jargon used by administration and conformity should be considered together. It is interesting that as long as conformity is maintained, the message of administration can be received. Otherwise, the rights might be lost. Public sphere assumes contemporary self-management principle based on critical thinking and consent. Wholeness aims at managing itself and apart from giving importance to reciprocity; it is the domain of equal participation and free discourse. Public sphere always resists the pressures of both dominant state and capital. Moreover, public sphere is a domain where ideas and actions are shared in social life. Thus, public sphere includes various concepts, such as public opinion, daily practices and culture.

All democratic societies regard communities and nations as having public aspects. On the other hand, it is assumed that there are domains public spheres, which have been formed by collective subjects. Social media too refers to these new domains brought to the top by social media. However, expected to be independent and democratic, social media has begun to be questioned as it is continuously monitored and controlled. In fact, social media appears as an area where poems, discourses and emotions are shared, which provides a kind of shelter for individuals to get away from the real world. Başsoy (2011) mentions what Conan O'Brien, American talk show host and writer, once said: "the 
Egyptian Government shut down Twitter during the riots in Egypt. However, there is only one way to send the rioters back their homes:"to re-open Twitter".

The views on social media are sometimes expressed instantaneously without revealing identities; thus, they are usually temporary. Different topics are mentioned by different people continuously. Similarly, sober judgments, odd replies or observations can also be seen. However, collective discourses and actions on social media have no continuity at all. Besides, such views do not bring about any sanctions. Therefore, social media appears as a kind of relaxation area. Here the aim is not to convince each other, but use the socalled area of freedom transiently.

According to Habermas (as cited in Slattery, 2003/2007, p. 437), public sphere is an area where individuals think and ponder about common topics, participate in sensible discussions and come to conclusion on particular issues through particular processes, means and situations. Nevertheless, critical stance against technology is in contrast with the view that computers will reshape public life, because he discusses that science and technology are used not only to abuse humanity and nature, but also increase the profit as well the social control of monopolist capital. Furthermore, science and technology are developed in accordance with the interests of corporations rather than the benefit of humanity. Although it is claimed that the Internet or social media create a public sphere emancipating individuals, surveillance over social media networks refutes this thesis.

In today's economic world, less than a million of elites control $80 \%$ of the world's riches. Most of this control is exercised by means of the ownership of press and TV, publishing, film production companies as parts of media holdings that have a thrilling power. According to Pilger (2002), [media companies] transformed most of "the information society" to a media age which allows the repetition of politically "secure" information and makes "nation builders" of extraordinary technology acceptable. Pilger (2002) also asserts that "global economy" is the most important enterprise of the media.

Dystopia is usually defined as authoritarian or rather totalitarian administration along with oppressive social control to create a better and probably a perfect society even at the expense of contradiction to humanistic approaches and attempts. Today, many societies transform to dystopias or antiutopias through globalization ideology. In this sense, it would not be wrong to suggest that globalization ideology and anti-utopias with respect to a warning to mankind display similar aspects. The similarities between anti-utopias and globalization ideology are usually around technological developments, control and manipulation over individuals, suspicion related to the reliability of structured information, lack of confidence, consent to dominant power and loss of values. From economy-political perspective, social media and the Internet might be considered as a means contributing to anti-utopias.

The new conception of economy has always indicated the new order it exists. According to Atabek (as cited in Güngör, 2011, p. 175) with the introduction of the new conception of economy, the traditional relationship of the capitalist age between labor and capital has ended and it has been replaced 
by a new global order determined by the ownership of knowledge. Güngör (2011) has mentioned that what is meant by information society is nothing but the conceptualization of capitalism by Bill Gates. In his book, Gates draws attention to various points that have arisen as a result of communication technologies, namely new researches for business, new relationships at work, new way of working, new production relationships and new trends in bureaucratic structure.

According to Güngör (2011) in today's world surrounded with computer technology, the issue that can be associated with ethics is simply privacy. In other words, privacy managed to remain unchanged in the world where capitalism made everything a commodity until the threatening advent and development of audio-visual techniques. As a result, capitalism has the potential power based on the observer and the observed. On the other hand, under the respective power relations lay the economic conditions. The Internet along with e-mail service is one of the most effective areas where privacy is concerned. It is not only the content which is conveyed via these addresses; each address is a matter of privacy. In addition, from the perspective of corporations, the time that employees use to read the mails is loss of labor in economic sense. The discussions, particularly those of Marxist fractions about communication technologies, stress the hegemony of the developed countries over the underdeveloped ones by means of technology and draw attention to the fact that neo-colonization grows up on the basis of technology.

As Güngör (2011) suggested, although the world seems to be getting uniformed, in fact it is going through differentiation and fragmentation. It is the line between knowledge and lack of knowledge that divides and fragments the world. Meanwhile, globalization is just a camouflage. In a world where technology is developing very fast, "McLuhan's utopia has been replaced by Orwell's black utopia. Computer technologies have increased the surveillance and control of individuals almost everywhere to such an extent that they feel as if they are watched even in their private spheres by an electronic eye" (Lyon as cited in Güngör, 2011, p. 177). The earthshaking Wikileaks incident has clearly shown that people are enslaved by the technology they have created. However, it should be remembered that technology is just a means. In fact, the crucial matter is the power and benefit relationships among those who use the power. Moreover, social media contributes to the strengthening of hegemonic relations. While the communication between the dominant powers and people is getting easier thanks to social media, those who are governed unconsciously recognize this dominance with their own consent. Joining the fan sites of politicians and expressing the admiration, promoting approval and solidarity all refer to the concept of consent as suggested by Gramsci. Thus, social media functions as a domain of hegemonic relations. To some extent, social media can be regarded as an informal area of communication. The diffusions and relations at different levels in this media might also be useful for the analysis of the alliances formed in modern societies. Apart from their ethnic and religious origins, individuals get into communication and interaction in the areas based on similarities along with communities, groups and societies. It should be 
noted that they may encounter contradiction and threat with respect to the domains of such alliances formed by numerous groups (Güngör, 2011).

People from different backgrounds can meet each other by means of social media and these encounters may even in marriage. Today, it may be claimed that social media both strengthens and also weakens family structure. Parallel to the developments on social media, colonization through language has been more conspicuous. Social media may play a role for the diffusion and reproduction of dominant culture. In addition, social media has transformed the consumption styles along with shopping habits. As a result of the facilitation of shopping on the Internet, consumers may easily fall into the trap of consumerism. Similarly, due to quick and easy payment opportunities, they buy many things that they do not relay need. Consequently, a hyperconsumption society is unavoidably created, which refers to the characters in anti-utopias, who has lost their individuality and rationality. As Güngör (2011) has stated, the other side of the transformations towards anti-utopias can be noticed in consolidation of the top levels of hierarchical orders, the divisions and disorders in society as well as the inequality in access to the information on the net and social media. Different sectors in a society that do not have equal opportunities will eventually begin to disappear and as a result, fragmentations strengthen the hierarchical order and freedoms are restricted.

Overall, restrictions on freedoms unavoidably lead to the disintegration of social values. The members of a society that feels continuous oppression is somehow obliged to express themselves by resorting to violence. By means of social media which provides the comfort of getting away from facts, the practice of violence becomes rather easier. Since social media creates the dilemma of being somewhere and also not really being there, individuals may normalize violence by continually being exposed to loss of values in this hazy reality As violence heightens, more restrictions on freedoms are imposed, which in turn brings about a vicious circle.

\section{Method}

Regarding the purpose of assessing the media coverage pertaining to the news in which social media and violence coincide, the news in three Turkish newspapers, namely, Zaman, Posta and Hürriyet have been examined with content analysis method for a three-month period, between November $1^{\text {st }}$ and February $28^{\text {th }}, 2014$. The respective sampling was determined according to the highest circulation rate.

Initially, the news in which social media and violence coincide has been selected. For this purpose, the pieces of news were chosen in these three newspapers according the extensive definition of violence. In order to find out the pieces of news about violence, some key concepts have been determined among various definitions of violence:

1. The act or an instance of violent action or behavior. 
2. Exertion of abusive or unjust, unwarranted or unlawful force for the purpose of violating and damaging.

3. Abuse or injury to meaning, content or intent.

In this regard, the news about social media has been held with respect to the following categories:

1. Social media as the generator of violent acts (social upheavals, misdemeanors, domestic violence, cyber-bullying etc.).

2. The use of social media to create and exert physical as well as emotional harm and disturbance with respect to the aggrieved parties.

Social media can be used to raise consciousness against violence within the context of media literacy. Thus, the news was examined both thematically and lexically. Concerning the beginning, the news containing the themes above was determined. Then, a content analysis was carried out according to lexical items in each piece of news, which pertain to the definitions of violence.

Firstly, the ratio of the news in which social media and violence coincide was determined in the three newspapers chosen according to the highest circulation rate as the sampling of this study. Then, the news topics were analyzed in order to find the weighty issues in the three newspapers and the ratio of the issues has been calculated with regard to the total number of the news where social media and violence overlap. Topics were arranged in the following categories:

1. Internet content including sex and violence-sharing and spreading obscene material.

2. Internet addiction.

3. Desensitization to violence.

4. Problems of interpersonal relationships.

5. Cyber-bullying.

6. Hate speech through social media.

7. Social media investigating violence particularly during public upheavals-sports.

8. Social media as a preventive factor against violence.

9. Others including the impact of electronic media violence along with the prevalence and predictors of internet bullying as well as electronic media and violence as an emerging public health problem.

Finally, keeping in mind the fact that news form and news content is quite inseparable from each other; a further analysis has been done in order to find the news actors in the respective news. The following actors were identified as:

1. Experts/specialists. 
2. Protestors/activists.

3. Non-profit organizations.

4. Columnists/reporters.

5. Others.

\section{Evaluation}

As a preliminary step, the ratio of news coverage for the issues on violence and social media has been determined (Figure 1).

Figure 1. Ratio of News on Violence in Posta, Hürriyet and Zaman

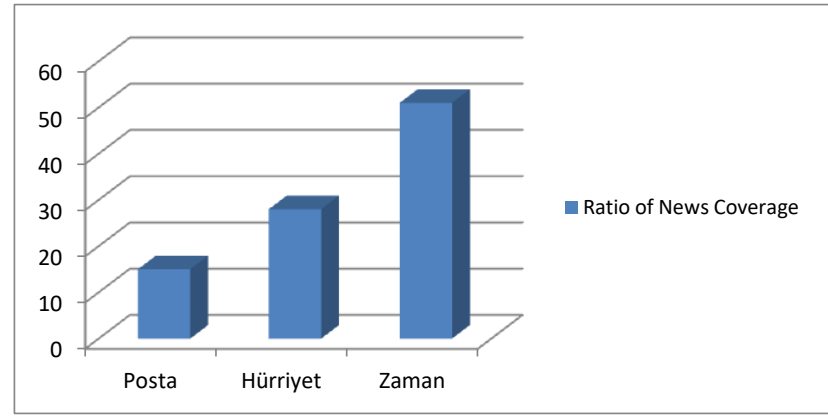

The reason for the relatively high ratio of the news on violence and social media in Zaman results from a quite extensive coverage for this issue through in-depth interviews and analyses. As a prominent topic, it is pointed out that those who are exposed to violence particularly on the Internet are more likely to perpetrate violence.

The news coverage in Posta, as a tabloid newspaper, is usually around fights, quarrels, attacks and even murders committed as a result of sharing or dispensing particularly private information on social media along with the mobbing through the Internet.

As a mainstream newspaper, Hürriyet, usually highlights the views of the experts on social media and violence and features the question whether or not social media can be utilized to help prevent violence in social life, sports and schools. These experts are academics and specialists in the fields of education and human development, public policy and higher education, teaching and learning, as well as psychology and human development. While the same approach seems to be observed in Zaman by voicing the views of the academics, there is an overt preponderance of the news related to social media oriented acts of violence in Posta.

Briefly, parallel to the intellectual level of the newspapers, how the respective issues are held shows difference. A more detailed analysis pertaining to the total ratio of the news topics correlated with violence in the respective newspapers can be seen in Figure 2. 
Figure 2. Ratio of News Topics Correlated with Violence

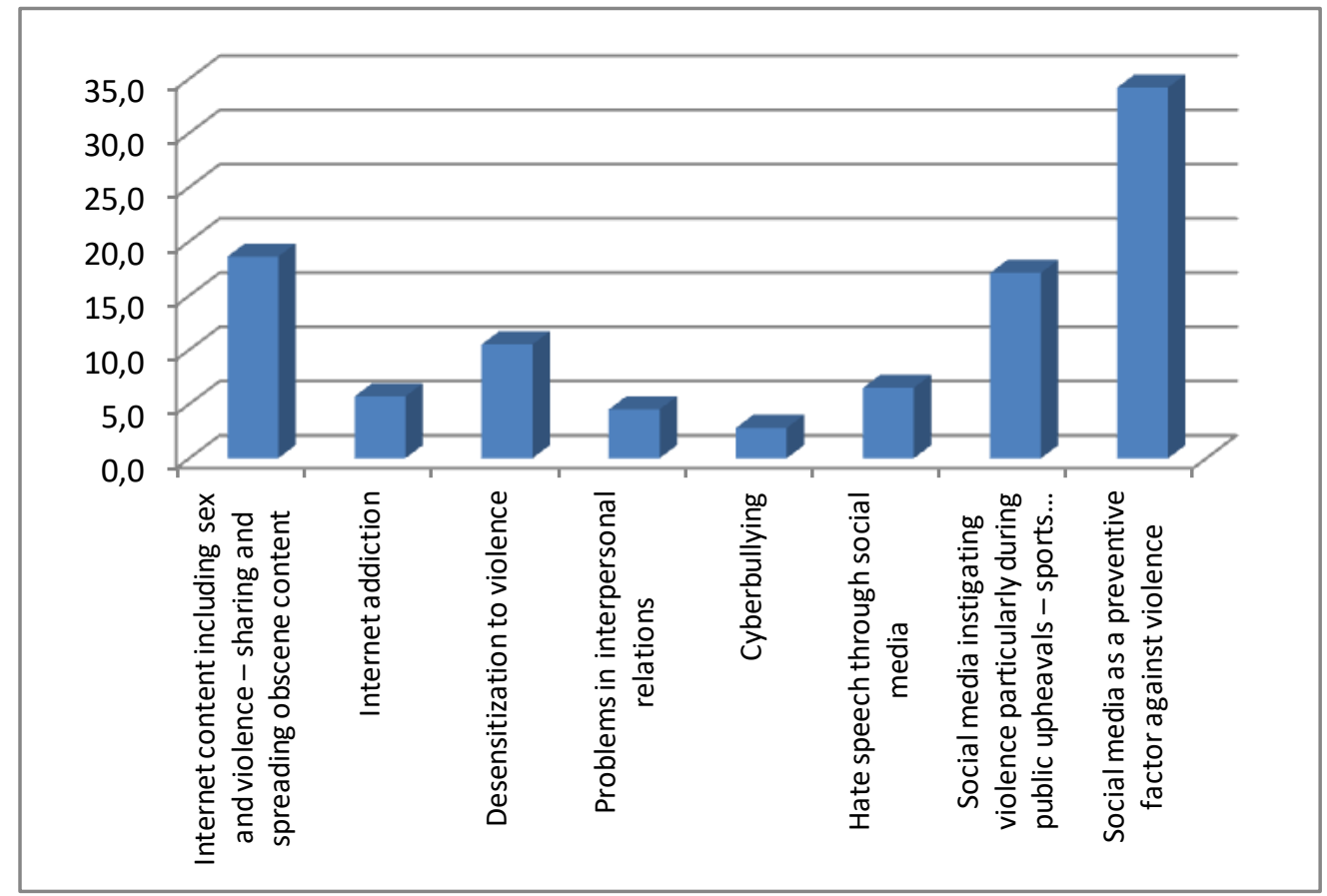

Considering the overall news coverage in the respective newspapers, social media functioning as a preventive factor against violence seems to be most frequently mentioned issue through the views of experts and specialists. Generally speaking, it is highlighted that unconscious or uncontrolled use of the power of social media may lead to the spreading of hate speech, infringement of personal rights, psychological attacks, symbolic violence, broadcasting private visions without the consent of the interested parties, deceiving people with fake accounts, spread of negative discourses intending to abuse, harassment and insult along with the circulation of malevolent views and information.

As a preventive factor against violence, social media appears as an area for protesting the excessive use of power by the police. In this context, the suggestions of the EU about including civil society to decision making mechanisms in a more institutionalized way along with the dismay for the violence exercised by the police as well as the acts of violence committed by the demonstrators organized on social media have been displayed.

Another example related to this category can be given as setting agenda on social media by the Turkish Temperance Society as a result of excessive consumption of alcohol leading to an escalation not only in the rates of traffic accidents, but also the acts of violence.

Consideration of people for stray animals has also been expressed through social media within the context of preventing cruelty to animals. Similarly, social media has been suggested as an alternative to prevent violence particularly in football. 
Moreover, pressure over social media helped postpone the execution of a religious leader in Bangladesh. It was also mentioned that if the execution were realized, acts of violence would appear.

It is not surprising that the second issue referred widely in the respective newspapers is the Internet content including sex and violence, particularly sharing and spreading obscene content. The most important threat to young people and children is seen as the adult sites, social networks containing violence and sex, which may even stimulate early adolescence along with psychological disorders.

The students who have been exposed to violence tend to exercise violence on the others. Sometimes quarrels even fights among young people arise even as a result of sharing stuff on social media. For instance, the legislative proposal by a German MP against mobbing on Facebook-video recording and sharing without the consent of related parties particularly during classroom activities- has been mentioned

The most dangerous means of violence are seen computer games and videos, which arouse sympathy towards violence, which may easily lead to desensitization to violence.

Pretty low ratio of media coverage about this problem indicates that although there are a considerable number of especially young people suffering from cyberbullying, it is not known as a concept yet. As for hate speech on social media, Instigating and displaying violence against certain (religious) groups, particularly women through social media has been given coverage.

An evaluation with respect to the total ratio of news actors in the news including social media and violence in Zaman, Hürriyet and Posta can be seen in Figure 3.

Figure 3. Total Ratio of News Actors in the News, including Social Media and Violence in Zaman, Hürriyet and Posta

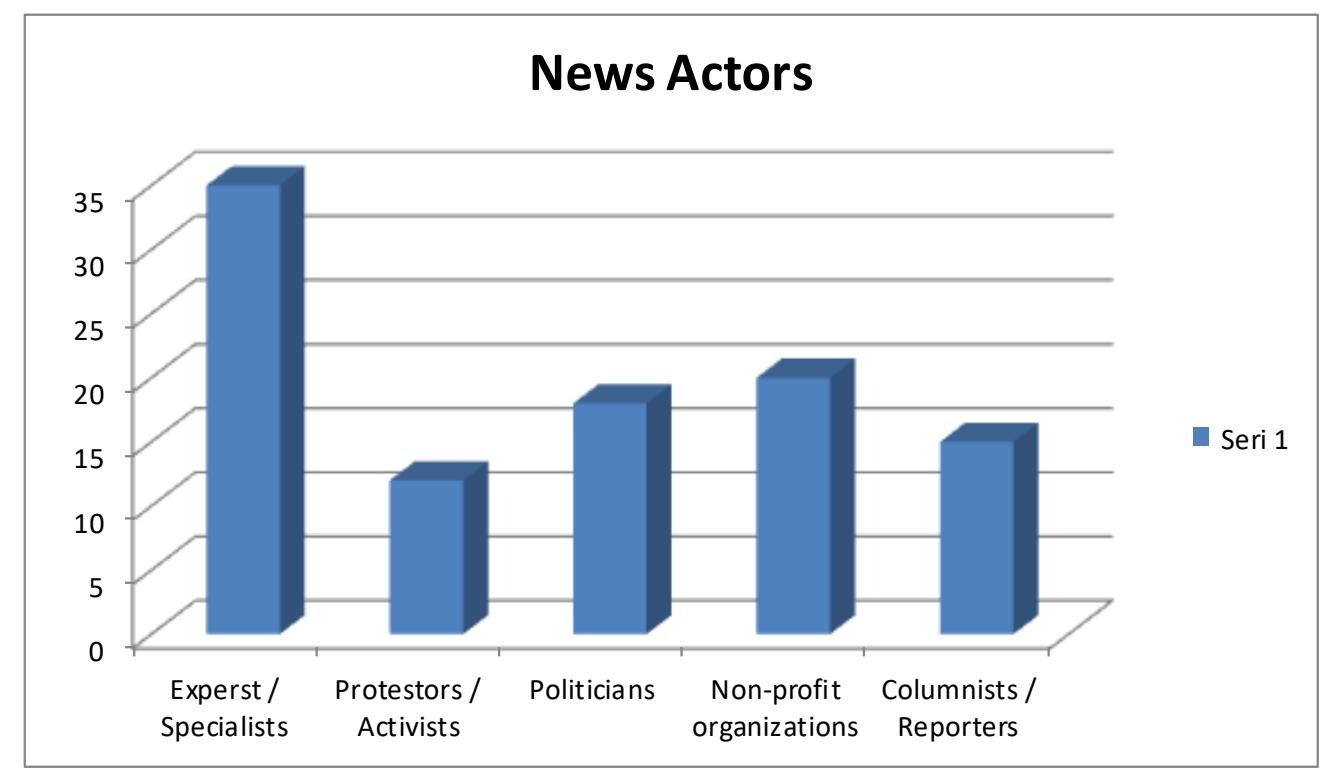


As for the news actors, the most frequently referred news actors are experts and specialists, including media professionals, psychologists, psychotherapists, counselors, academics and also a legal expert of informatics. Overall, it can be inferred that the newspapers have a rather objective attitude towards violence and social media through the views of professionals.

Secondly, non-profit organizations are also mentioned as they voice their concern about certain social issues or launch campaigns to raise awareness towards serious problems. As for some examples, Reporters without Borders, Society for the Prevention of Cruelty to Animals, manageress of a women's refuge, the Committee to Protect Journalists (CPJ) can be given.

How politicians are referred in the news about social media and violence is quite interesting, because there seems to be a common complaint even charge from the government side towards social media as it is accused of spreading innuendo, rumor and slander as well as instigating violence. Contrary to this approach, opposite parties or sides accuse the government for exercising surveillance and oppression over social networks. Finally, the relationship between social media and violence is also pointed out through the reports and comments of reporters and columnists.

Today more and more people own at least one form of new media technology and they use it with increasing commonness. The outbreak of technology and its use by ever increasing people undoubtedly brings about various potential benefits that mainly include connectedness and accumulation of knowledge on a large number of topics. However, the new forms of media technology have the potential risk of being misused or even abused. In other words, people may easily fall victim to the embarrassment, aggression, harassment and even threats of physical abuse. Such a risk, in fact, has been capturing vast attention.

\section{Conclusions}

Social media that is supposed to contribute to the maintenance of societies where democracy and multiplicity prevail could be an effective means for structuring, directing and internalizing the given ideology. Although the internet or social media are supposed to create a public sphere emancipating individuals, the fact that the social media networks are under control and surveillance refute the thesis that those virtual media are really open forums. Besides, the content incorporating violence does not only produce negative effects on the users but also makes them somewhat dysfunctional.

Nevertheless, unconscious or uncontrolled use of the power of social media may lead to the spread of hate speech, infringement of personal rights, psychological attacks, symbolic violence, broadcasting private visions without the consent of the interested parties, deceiving people with fake accounts, spreading negative discourses intending to abuse, in addition to mobbing, harassment and insult along with the circulation of malevolent views and information on the Internet.

Although it was introduced at the beginning of 2000's in Turkey and is still in its infancy, media literacy seems to be given prominence gradually in 
printed media through the views of experts and specialists. It might be inferred that there is an attempt to raise consciousness toward the potential threat that unconscious and uncontrolled use of social media may bring about. Thus, regarding the news coverage pertaining to violence and social media, the respective issues seem to be held quite objectively to draw the attention of the public to the potential threats that the abuse of social networks may cause as well as to raise consciousness for media literacy instead of merely vilifying social media. In this respect, preventive and protective measures against the offensive content as well as reasonable and proper use of social media are highlighted.

\section{References}

Baban, E. (2012). McLuhan ve Baudrillard'ın penceresinden sosyal medyanın etkisi: Ifadenin esareti, gözetlenen toplum, kayıp kimlik sendromu [The influence of social media from the perspectives of McLuhan and Baudrillard: Captivity of expression, observed society, lost identity syndrome]. In T. Kara \& E. Özgen (Ed.), Sosyal Medya [Social Media] (pp. 57-79). İstanbul: Beta.

Başaran, F. (2010). İletişim Teknolojileri ve Toplumsal Gelişme [Communication Technologies and Social Development]. Ankara: Ütopya.

Başsoy, A. (2011). Haberleşme Çağında Galeyan [Rage in the Age of Communication]. İstanbul: Birikim.

Berson, I. R., Berson, M. J. \& Ferron, J. M. (2002). Emerging risks of violence in the digital age: Lessons for educators from an online study of adolescent girls in the United States. Meridian: A Middle School Computer Technologies Journal, 5(2). Retrieved from http://www.ncsu.edu/meridian/sum2002/cyberviolence/6.html

Best, P., Manktelowa, R., \& Taylor, B. (2014). Online communication, social media and adolescent wellbeing: A systematic narrative review. Children and Youth Services Review, 41, 27-36. Retrieved from www.elsevier.com/locate/childyouth

Bock, J. G. (2012). The Technology of Nonviolence: Social Media and Violence Prevention. Cambridge, MA: The MIT Press.

Florea, M. (2013). Media violence and the cathartic effect. Social and Behavioral Sciences, 92, 349-353. doi: 10.1016/j.sbspro.2013.08.683

Görzig, A., \& Frumkin, L. (2013). Cyberbullying experiences on-the-go: When social media can become distressing. Cyberpsychology: Journal of Psychosocial Research on Cyberspace, 7(1). doi: 10.5817/CP2013-1-4

Güngör, N. (2011). Sanal Ortamda Iletişim: Bir Halkla Ilişkiler Perspektifi [Communication in Virtual Medium: A Public Relations Perspective]. Ankara: Siyasal.

Heath, J., \& Potter, A. (2012). Isyan Pazarlaniyor [The Rebel Sell]. (T. Tosun, Trans.). İstanbul: Ayrınt1. (Original work published 2004)

Kazanc1, M. (2001). Kamuda ve Özel Sektörde Halkla Ilişkiler [Public Relations in State and Private Sectors]. Ankara: Turhan.

Motion, J., \& Leitch, S. R. (2007). A toolbox for public relations: The oeuvre of Michel Foucault. Public Relations Review, 33(3), 263-268. http://dx.doi.org/10. 1016/j.pubrev.2007.05.004 
Patton, D. U., Eschmann, R. D., \& Butler, D. A. (2013). Internet banging: New trends in social media, gang violence, masculinity and hip hop. Computers in Human Behavior, 29, A54-A59. http://dx.doi.org/10.1016/j.chb.2012.12.035

Pilger, J. (2002). The New Rulers of the World. Verso. Retrieved from http://www. thirdworldtraveler.com/Pilger John/New Rulers World.html

Postman, N. (1994). The Disappearance of Childhood. New York, NY: Random House.

Sennet, R. (2009). Yeni Kapitalizmin Kültürü [The Culture of the New Capitalism]. (A. Onacak, Trans.). İstanbul: Ayrıntı. (Original work published 2006)

Slattery, M. (2007). Sosyolojide Temel Fikirler [Key Ideas in Sociology]. (Ü. Tatlıcan, Trans.). İstanbul: Sentez. (Original work published 2003)

Üşür, S. S. (1997). İdeolojinin Serüveni [The Adventure of Ideology]. Ankara: İmge.

Van Laer, T. (2014). The Means to Justify the End: Combating Cyber Harassment in Social Media. Journal of Business Ethics, 123(1), 85-98.

Violence. (n.d.a). In Blackwell Encyclopedia of Sociology Online. Retrieved from http://www.sociologyencyclopedia.com/public/search?query=violence

Violence. (n.d.b). In Merriam Webster - An Encyclopedia Britannica Company. Retrieved from http://www.merriam-webster.com/dictionary/violence

What is Cyberbullying. (n.d.). Retrieved from http://www.stopbullying.gov/cyberbul lying/what-is-it/

Yanıkkaya, B. (2009). Gündelik hayatın suretinde: öteki korkusu, görsel şiddet ve medya [The representation of daily life: the fear of the others, visual violence and the media]. In B. Çoban (Ed.), Medya, Milliyetçilik, Şiddet [Media, Nationalism, Violence]. İstanbul: $\mathrm{Su}$.

Ybarra, M. L., \& Mitchell, K. J. (2004). Youth engaging in online harassment: Associations with caregiver-child relationships, Internet use, and personal characteristics. Journal of Adolescence, 27(3), 319-336. Retrieved from http:// www.unh.edu/ccrc/pdf/jvq/CV63.pdf 
